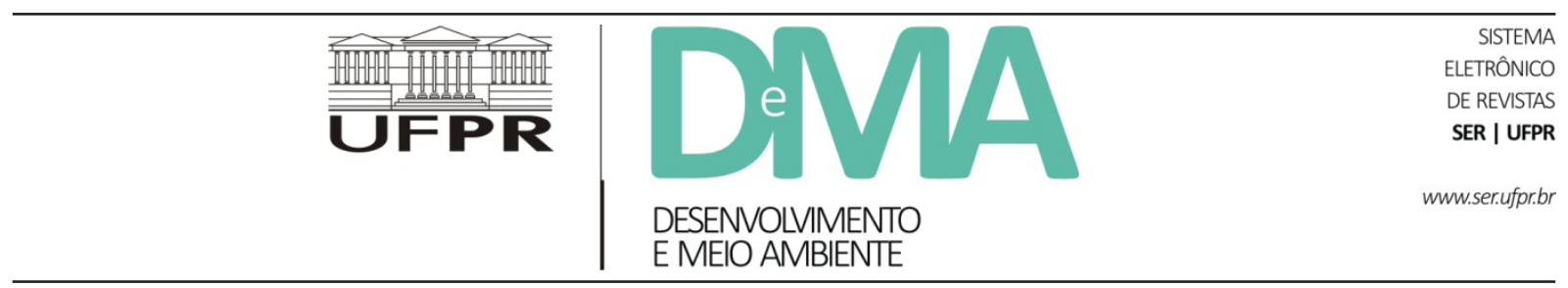

\title{
Editorial
}

\section{Gestão Integrada de Áreas Litorais: Governança para os Serviços Ecossistêmicos das Costas e Oceanos}

\section{Integrated Management of Littoral Areas: Governance for Ecosystem Services of Coasts and Oceans}

O II Congresso Ibero Americano de Gestão Integrada de Áreas Litorais (II GIAL), ocorrido em maio de 2016, em Florianópolis, SC, trouxe à luz discussões de grande importância para a governança dos serviços ecossistêmicos dos nossos oceanos e costas. O evento contou com 454 participantes, entre cientistas, gestores, servidores públicos, funcionários, empresários, acadêmicos e representantes de organizações não governamentais de 16 países da Ibero-América.

Segundo a Declaração de Florianópolis, documento que traduz os resultados gerais dessas discussões, os mares e as costas da Ibero-América têm sofrido, de forma crescente, os efeitos da escassez de energia, do câmbio climático global, do modelo econômico dominante, da crescente desigualdade na distribuição da riqueza, do notável crescimento da população e da perda de serviços promovidos por ecossistemas. Esta problemática gera um panorama complexo de difícil solução, que deve ser abordado para que a sustentabilidade se estabeleça, de fato, nos espaços socialmente estratégicos da zona costeira.

O II Congresso Ibero Americano de Gestão Integrada de Áreas Litorais enfatizou a necessidade de uma gestão com base ecossistêmica (GBE), sendo esta um enfoque que combina o bem-estar dos seres humanos com a saúde do meio ambiente. A GBE traz o conceito de que os ecossistemas proporcionam valiosos serviços naturais ou "serviços ecossistêmicos" para as comunidades humanas, reconhecendo sua complexidade, suas conexões, os vínculos com a terra e com a água doce, assim como sua integração com a sociedade. Sua aplicação no meio marinho e costeiro é relativamente nova e se estabelece em resposta ao estado de progressiva deterioração desses sistemas naturais. A manutenção dos serviços desses ecossistemas é essencial para a preservação da biodiversidade e das atividades socioeconômicas na região.

Neste sentido, os trabalhos apresentados para esta seção especial da Desenvolvimento e Meio 
Ambiente refletem pesquisas e trabalhos que vêm sendo realizados no âmbito da gestão costeira. Eles foram apresentados numa sequência tida como "natural" para o tema: (1) Base de informação (Veiga Lima e colaboradores), (2) Usos e impactos na zona costeira (Sfredo e Tagliani, Bezerra e Franz, Rios e colaboradores), (3) Planejamento (Figueiroa e Scherer, Tagliani), (4) Gestão (Mascarello e colaboradores, de Menezes e colaboradores) e (5) Avaliação da gestão (Figueiroa e colaboradores).

Veiga Lima e colaboradores apresentam o desenvolvimento de um modelo conceitual para identificação dos serviços ecossistêmicos de um importante sistema ambiental, na Ilha de Santa Catarina, as dunas. O trabalho expõe os principais serviços, atores beneficiados e vetores de pressão associados às dunas, demonstrando a importância dos ambientes costeiros para o bem-estar humano. Dentro do contexto da Gestão com Base Ecossistêmica, esta informação é de extrema importância para a tomada de decisões.

Da mesma forma, o trabalho "Análise das modificações ambientais decorrentes da ocupação urbana em Rio Grande, RS, entre 1947 e 2014, através de um Sistema de Informações Geográficas", de Sfredo e Tagliani, fornece subsídios importantes para a tomada de decisão no que concerne ao planejamento de atividades impactantes, em especial o porto de Rio Grande, e ao uso sustentável dos ecossistemas presentes.

Já Bernardino e Franz discutem sobre um dos maiores problemas da atualidade para o meio marinho, trazendo uma análise sob uma retrospectiva histórica e perspectivas para o futuro do problema do lixo flutuante na Baía de Guanabara. Os autores chamam a atenção, mais uma vez, para a necessidade da gestão integrada das áreas urbanas e do meio marinho, levando-se em conta as bacias de drenagem e suas influências na zona costeira.
Outro tema de grande relevância para as zonas costeiras e que também traz à tona a conexão terra-mar foi desenvolvido no trabalho "Vulnerabilidade física de parte do litoral leste do Ceará à erosão", de Marino e colaboradores. Este trabalho também traz a conexão entre a ocupação humana da costa e seus efeitos nos processos atuantes no sistema praial e sua relação com a erosão costeira em cinco praias do litoral do Ceará. Os resultados obtidos demonstram que áreas que apresentam grau de vulnerabilidade muito alto coincidem com as células e setores mais urbanizados, sugerindo um controle muito mais antrópico do que natural sobre a vulnerabilidade. Estes resultados sugerem mais uma vez a necessidade de um planejamento urbano condizente com as especificidades dos sistemas ambientais costeiros.

Neste sentido o trabalho de Figueiroa e Scherer traz uma avaliação crítica do Plano Diretor de Florianópolis no entorno de uma das mais importantes Unidades de Conservação da Ilha de Santa Catarina. Pelos resultados apresentados, depreende-se que o planejamento urbano de Florianópolis se encontra, atualmente, em desacordo com a legislação ambiental em vigor, assim como com as legislações que envolvem prevenção às catástrofes naturais. Este quadro se repete em muitos municípios costeiros brasileiros, podendo levar à perda dos serviços ecossistêmicos, conduzindo a um cenário impactante não só à biodiversidade, mas também ao bem-estar social.

Como instrumento capaz de compatibilizar o desenvolvimento das cidades costeiras e a manutenção dos serviços ecossistêmicos, Tagliani traz o trabalho "Zoneamento Ecológico-Econômico da zona sul do Estado do Rio Grande do Sul", no qual aponta o ZEE como um documento necessário para o planejamento da zona costeira. Além disso, cabe ressaltar que o ZEE é um dos instrumentos previstos 
no Plano Nacional de Gerenciamento Costeiro do Brasil e deve ser desenvolvido para as três escalas administrativas - Federal, Estadual e Municipal.

No entanto, como demonstra o trabalho de Mascarello e colaboradores, muitas vezes existem conflitos entre instrumentos legais de planejamento territorial, tais como Plano Diretor Municipal, Zoneamento Ecológico Econômico Municipal - ZEEM, Plano Ambiental Municipal, Planos de Manejo de Unidades de Conservação. Os conflitos observados no estudo de caso da região do Balneário Cassino e adjacências, no município de Rio Grande-RS, vão desde problemas de escalas de análise diferentes entre os instrumentos para a delimitação de áreas de proteção permanente (APP) e a sobreposição destas áreas com as outras políticas públicas. Os autores concluem e evidenciam a importância da integração das instituições públicas e dos dados geoespaciais na regulação e na gestão do território.

Dentro da linha de planejamento espacial e da necessidade da participação pública neste processo, além de corroborar as conclusões gerais do artigo anteriormente mencionado, de Menezes e colaboradores trazem o estudo de caso do Projeto Orla no município de Balneário Rincão, SC, Brasil. Segundo os autores, três pontos foram destacados a partir da análise realizada: a necessidade de participação da comunidade no processo de gestão territorial; a necessidade de integração dos instrumentos de gestão; e que a educação ambiental é o principal instrumento de sensibilização.

Já Figueiroa e colaboradores adentram o planejamento da zona costeira pela ótica das unidades de conservação e a necessidade da integração da gestão destes espaços na zona costeira, realizando a discussão tendo como estudo de caso as Unida- des de Conservação marinho-costeiras de Santa Catarina. Os autores concluem que, apesar de haver algumas iniciativas de integração, a gestão das UCs ainda é fragmentada e com grau mínimo de integração, o que enfraquece o potencial das áreas de conservação na manutenção dos serviços ecossistêmicos costeiros e marinhos e no bem-estar humano.

O conjunto diverso dos trabalhos supracitados oferece a dimensão da tendência recente da gestão costeira. Em seu conjunto, eles destacam aspectos atuais e importantes, tais como o enfoque com base em ecossistemas, a preocupação com a degradação dos serviços ecossistêmicos por usos e impactos na zona costeira, a busca pela manutenção da qualidade dos sistemas costeiros e, finalmente, a compreensão da relação harmoniosa e necessária entre usos econômicos e natureza na busca do bem-estar social. Mais do que exemplos de produção científica, o conjunto de trabalhos aqui apresentados fornece uma objetiva demonstração de necessários estudos e iniciativas, como apregoado na "Declaração de Florianópolis".

Nossa expectativa é de que essa seção especial da Desenvolvimento e Meio Ambiente não só atue como uma plataforma de colaboração da academia à gestão marinha e costeira, mas também se configure como um estímulo a produções e iniciativas capazes de subsidiar políticas voltadas à sustentabilidade dos oceanos, costas e ilhas no Brasil e na Ibero-América.

\section{Boa leitura!}




\section{Equipe Editorial e Técnica responsável pelo volume:}

Organizadores da seção especial "Gestão Integrada de Áreas Litorais: Governança para os Serviços Ecossistêmicos das Costas e Oceanos": Marinez E. G. Scherer e Milton L. Asmus

Organizadores da seção especial "Social Inequalities within Protected Natural Areas: An International Perspective": Valérie Deldrève e Cécilia Claeys

Editores-chefes: Angela Duarte Damasceno Ferreira e José Milton Andriguetto Filho

Editores adjuntos: Frederico Monteiro Neves, Ricardo Ojima e Thiago Zagonel Serafini

Secretaria científica: Ana Paula Debastiani Vasco, Letícia da Costa da Silva, Roberta Giraldi Romano e Tatiana Cristina Guimarães Kaminski

Pareceristas da revista: ver em $<$ http://ojs.c3sl.ufpr.br/ojs2/index.php/made/about/editorialPolicies\# custom-2>.

Revisão de texto (português): Reinaldo Cezar Lima

Revisão de texto (abstracts): Fadille Terezinha Nabbouh

Editoração eletrônica: Reinaldo Cezar Lima

Design: Oscar Reinstein

ISSN: 1518-952X, eISSN: 2176-9109 